\title{
Comparison of In-Vitro Dissolution of Griseofulvin Tablet made from Nano Particles and Solid Dispersion
}

\author{
Nurul Karima ${ }^{1 *}$, Sumaiyah Sumaiyah ${ }^{1,}$ Azizah Nasution 2 \\ 1Department of Pharmaceutical Technology, Universitas Sumatera Utara, Medan, 20155, North Sumatera, \\ Indonesia \\ 2Department of Pharmaceutical Pharmacology, Universitas SumateraUtara, Medan, 20155, North Sumatera, \\ Indonesia
}

\begin{abstract}
A B S T R A C T
Objectives: To find out the comparison of dissolution results of griseofulvin tablets made from nanoparticles, solid dispersions, and conventional materials.

Interventions: Different types of active ingredients in the form of nanoparticles and solid dispersions can affect the dissolution results of tablets.

Main outcomes measure: The results obtained in this study are the cumulative dissolution percentage and the order kinetics of the release of active ingredients.

Conclusion: There was no significant cumulative percent drug release difference ( $p>0.05)$ between nano particles, solid dispersions, and conventional materials. Tablets containing active nanoparticles, solid dispersions, and conventional materials show a linear relationship with a correlation coefficient (R2) close to 1, shown in zero-order kinetics models.
\end{abstract}

Keywords: Dissolution, griseofulvin, nano particle, solid dispersion.

\begin{tabular}{ll}
\hline A R T I C L E I N F O: Received 07 Nov. 2019; Review Completed 21 Jan 2020.; Accepted 24 Jan. 2020; & Available online 15 Feb. 2020 \\
Cite this article as: & Karima N*, Sumaiyah S, Nasution A, Comparison of In-vitro Dissolution of Griseofulvin Tablet made from Nano Particles and Solid \\
Dispersion, Asian Journal of Pharmaceutical Research and Development. 2020; 8(1):11-13. & DOI: http://dx.doi.org/10.22270/ajprd.v8i1.644
\end{tabular}

Nurul Karima, Department of Pharmaceutical Technology, Universitas Sumatera Utara, Medan,North Sumatera, Indonesia

\section{INTRODUCTION}

A ccording to the World Health Organization (WHO) griseofulvin belongs to the Class II Biopharmaceutics Classification System (BCS), has low solubility and high permeability ${ }^{1}$. Drug solubility can determine the bioavailability of oral administration. Some conventional methods such as micronization, chemical modification, use of surfactants and solvents, solid dispersions, and some of the latest technologies such as cyclodextrin complexation, mucoadhesive microspheres, micro-emulsions, nanoparticles, and nanosuspensions can increase the bioavailability of class II BCS drugs ${ }^{2}$.

Solid dispersion system is one method that can be utilized in increasing the speed of drug solubility. Solid dispersion is a solid product consisting of at least two different components. In general, solid dispersions use hydrophilic matrices and hydrophobic drugs. This changes the drug into an amorphous form that can increase the rate of dissolution ${ }^{3}$.

Nanotechnology is a formulation approach to solubility and increased bioavailability by reducing particle size from 1 to $100 \mathrm{~nm}$. Reducing particle size is very beneficial for increasing site-specificity, increasing bioavailability, and reducing the possibility of side effects ${ }^{4}$.

Nanoparticles can be done by several methods, namely: crushing (grinding), grinding (grinding), spray drying (drying spray), and freeze drying (freeze drying) ${ }^{5}$. The most commonly used method is media mill which is a technology of particle size reduction and its reliability has been proven in several studies. 


\section{MATERIALS AND METHOD}

\section{Materials and Instruments}

The materials used in this study include: Griseofulvin (GR), Polyetylen glycol (PEG) 6000, sodium lauryl sulfate, Microcrystalline Cellulose (Avicel 102), Mg stearate, talcum, ethanol, methanol, aquades.

The tools used in this study include: laboratory glassware, stopwatches, analytical balance, mesh 40 , dissolution tester, tablet printing machines, and UV-spectrophotometers.

\section{Griseofulvin Solid Dispersion.}

The solid dispersion method used in this study is the Smelting method. In this method, griseofulvin and PEG 6000
(2: 8) are melted onto a water bath, then cooled quickly in an ice bath and stirred. After that, it is dried for 24 hours in a desiccator. Furthermore, the solid mass obtained is crushed, then sieved in mesh $40^{6}$.

\section{Griseofulvin Nano Particle}

Griseofulvin is put into a chamber where zirconium oxide granules are present, then the nanomill device is run at 600 rpm for 10 hours.

\section{Griseofulvin Tablet Formulation}

Formula in the preparation of solid dispersion and nanoparticle griseofulvin tablets using Mg. Stearic acid as a lubricant, talc as gluten, and Microcrystalline Cellulose (Avicel 102) are used as fillers and binder tablets.

Table 1: Formula for the preparation of Griseofulvin Solid Dispersion and Nanoparticle Tablets

\begin{tabular}{|l|l|l|l|l|}
\hline \multirow{2}{*}{ No. } & Materials (mg) & \multicolumn{2}{l|}{ Formula } \\
\cline { 3 - 5 } & & $\begin{array}{l}\text { Control } \\
\text { Conventional } \\
\text { Material) }\end{array}$ & Solid Dispersion & Nano Particle \\
\hline 1. & Griseofulvin & 17.5 & 17.5 \\
\hline 1. & Mg stearat & 20 & 20 & 20 \\
\hline 2. & Talkum & Microcrystalline Cellulose(Avicel 102) & 20 & 20 \\
\hline 3. & & & 442.5 & 345 \\
\hline Total & & & 500 & 500 \\
\hline
\end{tabular}

\section{Dissoluion Test}

Dissolution test of tablets using mixed media $40 \mathrm{mg}$ sodium lauryl sulfate in $1000 \mathrm{ml}$ of water. The dissolution speed of the dissolution device used is $75 \mathrm{rpm}$ in 90 minutes.

The tablets are put into a dissolution container which contains $1000 \mathrm{ml}$ of dissolution medium, temperature $37^{\circ} \pm 0.5^{\circ} \mathrm{C}$. Then the paddle is rotated at a speed of $75 \mathrm{rpm}$. In a certain time interval a sample is taken in the middle area between the surface of the dissolution media and the top of the rotating paddle, not less than $1 \mathrm{~cm}$ from the wall of the container as much as $1 \mathrm{ml}$ and put into a $25 \mathrm{ml}$ flask and diluted with a solution of methanol and water (4:1) to the mark line. Absorption is measured at a maximum wavelength of about $291 \mathrm{~nm}$. Medium volume was added as much as 1 $\mathrm{ml}$ after piping. Tests were carried out on 6 tablets.

\section{RESULTS AND DISCUSSION}

The results of in vitro griseofulvin drug release test using dissolution tester from solid dispersion and nanoparticle tablet formulas are shown in Figure 1. The drug release test results with griseofulvin nanoparticle system have higher cumulative percentages compared to standard griseofulvin and solid dispersion. This is due to the smaller particle size, so that the surface area will be larger. Larger surfaces allow greater interaction with the solvent and cause increased solubility ${ }^{8}$.

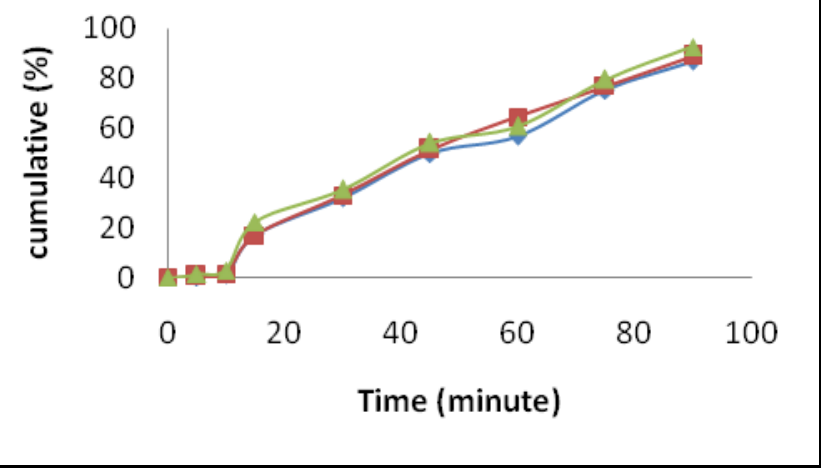

Conventional material

Nano Particle

Solid Disspersion

Figure 1. Average cumulative percentage of dissolution of conventional tablets, solid dispersions and griseofulvin nanoparticles

The results of the dissolution data obtained can be determined the release order kinetics carried out in 3 formulas, namely griseofulvin standard tablets, griseofulvin solid dispersion, and griseofulvin nanoparticles with four kinetic models (zero order, first order, Higuchi and Korsmeyer Peppas models. to determine the mechanism of drug release from formulated tablet preparations.In Table 2 shows the correlation coefficient (R2) value of each griseofulvin tablet formula. 
Table 2: Correlation coefficient values (R2) of the kinetic release of raw griseofulvin tablets, solid dispersions and nanoparticles

\begin{tabular}{|l|l|l|l|}
\hline Kinetic Model & Convensional Material & Soid Dispersion & Nano Partikel \\
\hline Orde nol & $\mathrm{y}=1.015 \mathrm{x}-1.756$ & $\mathrm{y}=1.055 \mathrm{x}-1.603$ & $\mathrm{y}=1.059 \mathrm{x}-0.080$ \\
& $\mathrm{R}^{2}=0.984$ & $\mathrm{R}=085$ & $\mathrm{R} 2=0.981$ \\
\hline Orde satu & $\mathrm{y}=0.0024 \mathrm{x}+0.137$ & $\mathrm{y}=0.023 \mathrm{x}+0.261$ & $\mathrm{y}=0.020 \mathrm{x}+0.444$ \\
& $\mathrm{R}^{2}=0.699$ & $\mathrm{R}=0.741$ & $\mathrm{y}=10.58 \mathrm{x}-16.93$ \\
& $\mathrm{y}=10.08 \mathrm{x}-17.57$ & $\mathrm{R}^{2}=0.932$ \\
\hline Higuchi & $\mathrm{R}^{2}=0.924$ & $\mathrm{R}=0.92 \mathrm{x}-18.19$ & $\mathrm{y}=162 \mathrm{x}-0.290$ \\
& $\mathrm{y}=1.319 \mathrm{x}-0.652$ & $\mathrm{y}=1.254 \mathrm{x}-0.500$ & $\mathrm{R}^{2}=0.900$ \\
\hline Korsmeyer-Peppas & $\mathrm{R}^{2}=0.829$ & \\
& $\mathrm{R}^{2}=0.762$ & & \\
& & & \\
\hline
\end{tabular}

The table above shows a linear relationship with a correlation coefficient (R2) close to 1, shown in the zero-order kinetics model. Drugs that follow the zero-order release kinetics describe an increase in drug concentration directly proportional to time. The zero-order kinetics model can be used to describe the release of several types of modification of drug dosage forms, such as: transdermal systems, matrix tablets in low solubility drugs 9 .

\section{CONCLUSSION}

There was no significant cumulative percent drug release difference ( $p>0.05$ ) between nano particles, solid dispersions, and conventional materials. Tablets containing active nanoparticles, solid dispersions, and conventional materials show a linear relationship with a correlation coefficient (R2) close to 1 , shown in zero-order kinetics models.

\section{CONFLICT OF INTEREST}

All author have no to declare.

\section{REFERENCES}

1. Lindenberg, M, Kopp S, Dressma JB. Classification of Orally Administered Drugs on The World Health Organization Model List of Essential Medicines According to the Biopharmaceutics Classification System. Eur. J. Pharm. Biopharm. 2004; 58(2):265-278.

2. Kumar, P, Singh, C. A Study on Solubility Enhancement Methods for Poorly Water Soluble Drugs. American Journal of Pharmacological Sciences. 2013; 1(4):67-73.

3. Zaini, E., MD Octavia, KR Wirza. Studi Sistem Dispersi Padat Meloksikam Menggunakan Hidroksipropil Metilselulosa (HPMC) 6 Centipoise (CPS). Jurnal Farmasi Higea. 2017; 4(2):52-73.

4. Sunder, S., Nair R. Methods of Nanonization of Drugs for Enhancing their Dissolution. Eur.J. Adv.Eng.Tech.2016; 3(8):101-110.

5. Wilczewska, AZ, Niemirowicz $\mathrm{K}$, Markiewicz $\mathrm{KH}$, Car $\mathrm{H}$. Nanoparticles as Drug Delivery System. Pharmacological Reports. 2012; 64(5):1020-1037.

6. Junghanns, JUAH, RH Muller. Nanocrystal Technology, Drug Delivery and Clinical Applications. Int J Nanomedicine. 2008; 3(3):295-310.

7. Bhowmik, D, Duraivel GHS, Kumar BP, Raghuvanshi V, Kumar KPS. Solid Dispersion- A Approach To Enhance The Dissolution Rate of Poorly Water Soluble Drugs.The Pharma Innovation-Journal. 2013; 1(12):24-38

8. Savjani KT, Gajjar AK, Savjani JK. Drug Solubility: importance and enhancement techniques. ISRN Pharm. 20122; 1:1-10.

9. Ramteke, KH, Dighe PA, Kharat AR, Patil SV. Mathematical Models of Drug Dissolution : A Review. Sch. Acad. J. Pharm. 2014; 3(5):388-396. 